Article

\title{
Causes of Oil Accumulation of Isolated Bars in Lacustrine Delta
}

\author{
Panpan Chen ${ }^{1}$, Cunlei $\mathrm{Li}^{2}{ }^{2 *}$, Jinliang Zhang ${ }^{3}$, Shengrong $\mathrm{Li}^{1}$, Guiyang $\mathrm{Ma}^{2}$ and Yang Zhao ${ }^{2}$ \\ 1 School of Earth Sciences and Resources, China University of Geosciences, Beijing 100083, China; \\ cpp1515@126.com (P.C.); 1995010290@cugb.edu.cn (S.L.) \\ 2 College of Petroleum Engineering, Liaoning Shihua University, Fushun 113001, China; \\ maguiyang@lnpu.edu.cn (G.M.); zhaoyangcdut@163.com (Y.Z.) \\ 3 College of Resources Science and Technology, Beijing Normal University, Beijing 100875, China; \\ jinliang@bnu.edu.cn \\ * Correspondence: licunlei@lnpu.edu.cn
}

Received: 26 January 2020; Accepted: 19 March 2020; Published: 21 March 2020

\begin{abstract}
After over 20 years of development in Daqingzijiang Oilfield, isolated sand bodies under the delta front and pro-delta in the Qingshankou Formation $\left(\mathrm{q}_{\mathrm{n}}\right)$ have become important oil and gas reservoir bodies. However, the cause for large amounts of isolated bar sand bodies in the lake-basin delta sediment system has not been reported in China. This article, through core observation, reveals plenty of evidence that there storm waves once existed. Combined with paleogeography and hydrodynamic force analysis, it describes the transformation effect of waves on delta sand bodies and on the formation mechanism of bar sand bodies. Based on a study on paleogeomorphology and the statistics of sand body distribution, we consider 'Storm waves conveying sand' and 'landform controlling sand' as the cause and distribution model of the delta's isolated bar sand body formation. We also think that the superposition of multiple bar sand bodies is the direct cause of the strong anisotropy in reservoirs and the complex relationship between oil and water in reservoirs. Most of these sand bodies have formed into lenticular lithologic hydrocarbon accumulations. On the basis of this integrated study on hydrocarbon accumulation, we set up an accumulation model of lenticular hydrocarbon accumulation involving the variables 'Surrounded by source rocks to generate hydrocarbon', 'Driven by pressure difference', 'Migration through multi pathways' and 'Accumulation by filtering water'.
\end{abstract}

Keywords: Daqingzijing Oilfield; delta; isolated sand bodies; sand-control mechanism; hydrocarbon accumulation

\section{Introduction}

At present, the exploration and development of most oilfields in China is shifting from the easily-developing conventional reservoirs to subtle lithologic reservoirs. However, subtle reservoir exploration is different from conventional reservoirs due to having increased difficulties in exploration and development. Reservoirs with a tectonic background in Daqingzijing Oilfield in Jilin Province have reduced well yield when the region's subtle reservoirs is low, and while it is hard construct these reservoirs productively, which are problems that are also being faced by most Chinese oilfields.

As further exploration and development of lithologic reservoirs (which are trapped by lithologic changes in the reservoir) produced by reservoir lithology changes and traps in Daqingzijing Oilfield have been conducted, it is becoming more and more obvious that the sand body distribution characteristics under the guidance of the theory of the sedimentary model of finger-like bar distribution does not match with productive practices, which seriously restricts exploration and development [1-3]. 
With core observation and description of over 60 wells in the study area, and on the basis of the comprehensive study on sand body distribution, this study suggests that the Qingshankou Formation in the Daqingzijing area has mainly developed into a highly destructive delta. Under the guidance of the model, we established distribution laws for isolated bars and discussed the cause of sand bodies in isolated bars. On the basis of a study on reservoir characteristics, we considered the fluid distribution characteristics of various reservoirs and established the lenticular reservoir accumulation model having the variables 'Surrounded by source rocks to generate hydrocarbon', 'driven by pressure differences', 'Migration through multi pathways' and 'Accumulation by filtering water'.

\section{Depositional Setting}

The Qingshankou Formation was formed from the first overall sinking and expansion of the Songliao Basin, and with obvious 'rushed beginning, slow ending' characteristics. Daqingzijing Oilfield lies in the center of Changling. The central depression area is in the south of Songliao Basin. The Changling Depression consists of two secondary depressions. One is the Qian'an Secondary Depression in the north and the other is the Heidimiao Secondary Depression in the south. The Daqingzijing Structure is on the middle of the two secondary depressions, clamped by Huazijing Terrace and Da'an-Honggang Terrace in the east and west. Daqingzijing Oilfield is interlinked with Qian'an Oilfield in the northeast and interlinked with the Qian 133 well area of Huazijing Terrace. In the south of the oilfield there is the south area of Heidimiao and in the northwest there is the Haituozi Oilfield of Da'an-Honggang Terrace (Figure 1). All these factors make Daqingzijing Oilfield an ideal regional tectonic location for rich oil and gas sources. Daqingzijing Oilfield is also a grand lithologic reservoir group of the Jilin Oilfield with over 100 million tons of oil and gas equivalent reserves $[4,5]$.

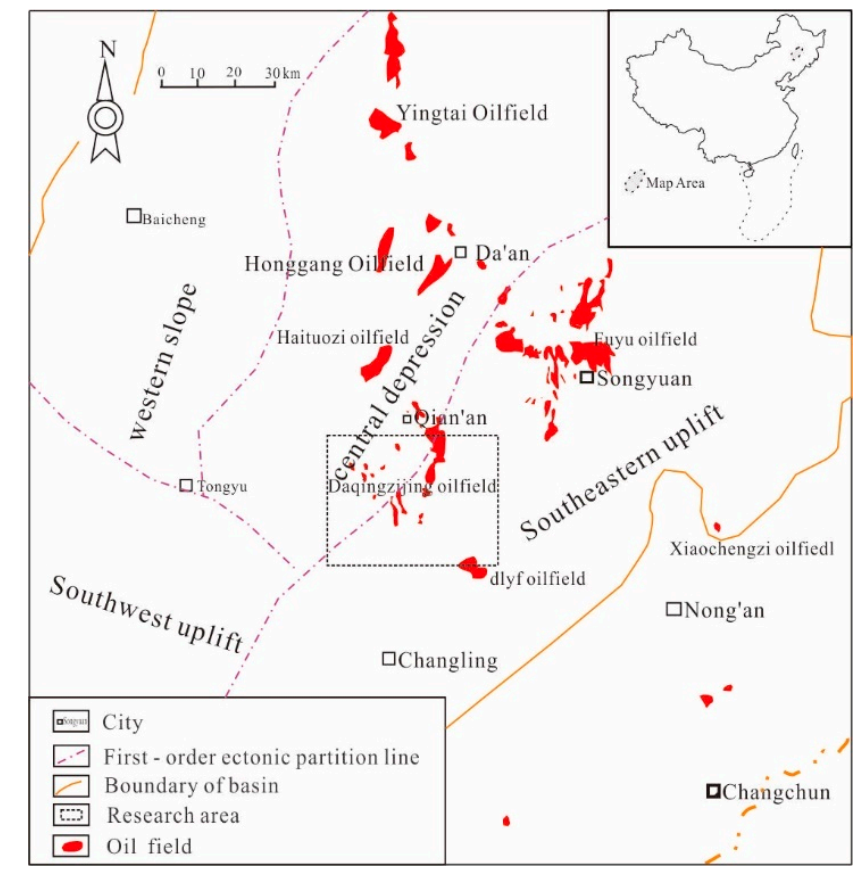

Figure 1. The regional tectonic location of Daqingzijing Oilfield [4,5].

During the sedimentary period of Qingshankou Formation sediment, the Songliao Lake Basin had a high rate of subsidence, the lake basin expanded, and the hot and dry paleoclimate became warm and humid. Sedimentary material provided by the Tongyu-Baokang river system from the southwest was formed into delta sediment in the Daqingzijing area. Under transgressive conditions, waves in the lake basin played an increasing role in the transformation of the existing delta system, which destroyed the sand bodies depositing before like diffluent pathways in the delta front, after which more uniform sand 
bodies in bars with the extensive reverse rhythm was formed. Only a few sand bodies with normal rhythms in the pathways remained. The sand bodies at the edge of river-mouth bars were transformed into ones with reverse rhythms separated from the main parts of bars, namely front bars. At the same time, sediment was re-deposited, which was re-carried by waves to form offshore bar sediment on offshore slopes and was connected with the delta front, forming highly destructive transgressive delta sediment transformed by (stormy) waves that are unique to the Daqingzijing area [6,7]. Controlled by sharp transgressive conditions, the delta sub-facies sediment in the transgressive delta system was narrow. When rivers converged into the lake, the delta front and pro-delta sediment formed. So to speak, the rivers did not form deltaic plain sediment in the lake shore before they were controlled by transgressive conditions and transformed into underwater reduction sedimentary environment, and thus they could not form typical delta plain facies tracts. During the mid- and later-periods of Qingshankou Formation sediment, the water body decreased gradually and delta plain sub-facies appeared (Figure 2).

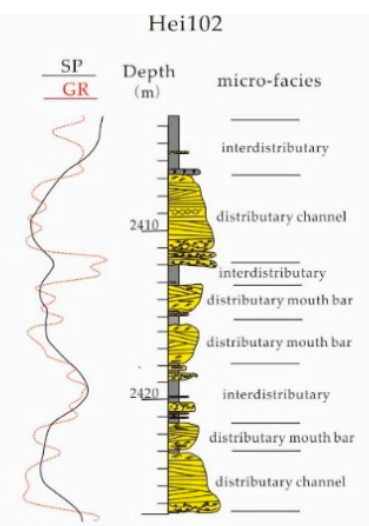

a

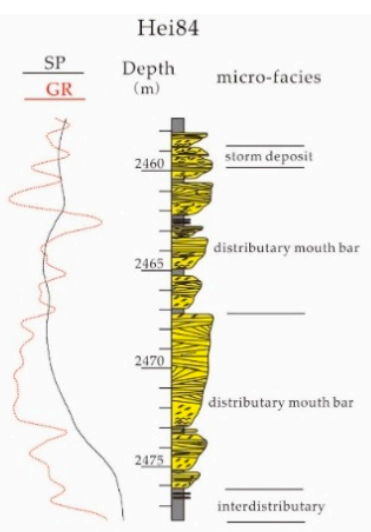

$\mathrm{b}$

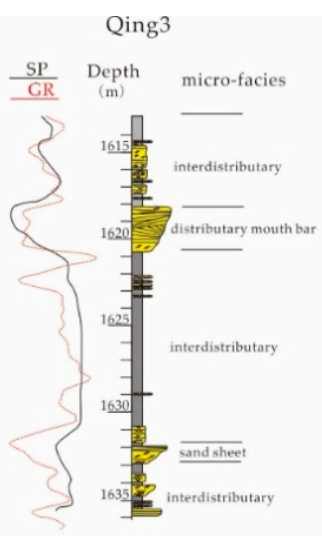

c

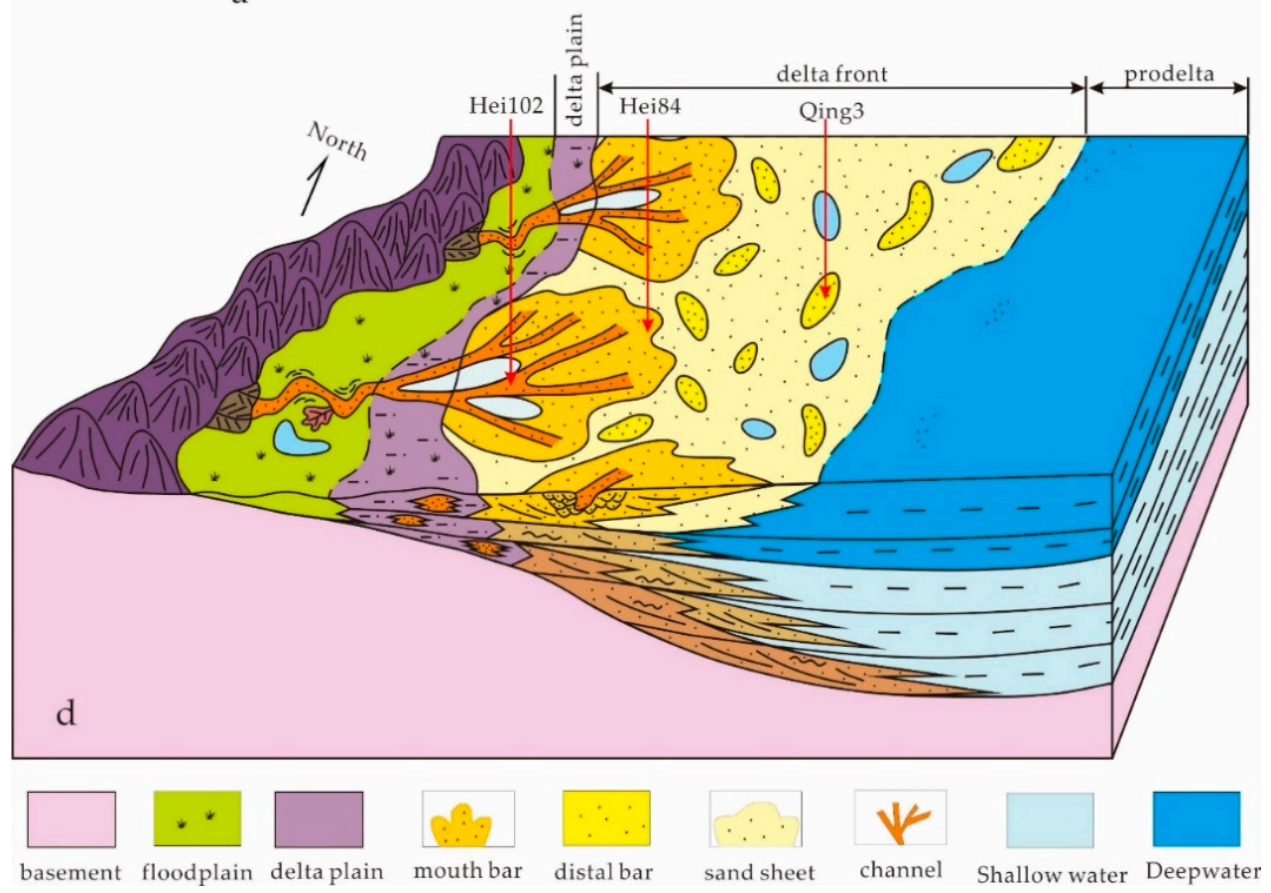

Figure 2. Sediment sequences and models of Daqingzijing Oilfield. (a) Single well facies analysis profile of Hei 102, showing the superposition sediments in a near provenance channel and bar sand bodies; (b) Single well facies analysis profile of Hei 84, showing the superposition sediments of bar sand bodies; (c) Single well facies analysis profile of Qing 3, showing the sand body sediments in argillite; (d)Highly destructive delta sediment model. 


\section{Distribution Characteristics of Isolated Sand Bodies}

By analyzing the statistics from 34 modern deltas and using several different parameters to describe the characteristics of basins, valleys, delta plains, and transgressive basins, Coleman and Wright established six separate delta models. Each of these models had a specific background and had unique sand body distribution patterns [8,9]. Among them, deltas of the VI type developed into bar sand bodies which are separate from delta sand bodies. Appalachicola Delta and Brazos Delta, which have mediate wave energy, a small tidal range, gentle offshore slopes, and a low supply of sediments, are typical examples of this type.

Few examples of highly destructive deltas that developed in lake basins have been reported around the world and the genetic mechanism is quite complicated. In the broad environment of lake basins, the cause of isolated bar sand body formation is similar to that of the sediment of beach bars. Feng et al. (2011) proposed that storm sediments played an important part in the formation of beach sand bodies [10]. Wang et al. (2012) put forward a genetic mechanism for beach bars in paleogeomorphology, paleohydropower, and paleobasal-level under the high-energy circumstances of shallow-shore lakes [11].

Starting with the study on the distribution pattern of sand bodies and combined with other studies on wave energy and basin bottom shapes, this article analyzed the cause of formation of encouraging bar sand bodies and referred to 'Storm waves conveying sand, landform controlling sand' as the formation cause of deltaic isolated bar sand bodies and their distribution models.

\subsection{Profile Characteristics and Horizontal Distribution Characteristics of Sand Bodies}

The core sequence directly presents the superposition relationship and characteristics of the sand bodies in isolated bars. The core shows that the sandstone lithology is mainly fine sandstone and siltstone, part of which is oil-spotted sandstone or oil-soaked sandstone. The bars are in gradual contact with mudstone at the bottom and in sharp contact at the top with a characteristic of obvious reverse rhythms from bottom to top. The bottom has mainly developed into wavy and lenticular beddings and is distributed as lacerate mud chips, deformation structures, nodules, and politic strips. The medium and upper parts are mainly made up of siltstone with wave-ripple beddings and water-ripple beddings, fine sandstone with parallel beddings, and mid-fine sandstone with low-angle cross beddings. Lamina of charcoal appears in some of sandstone members with occasional nodule developments. The thickness of the sand layers is between $2.5 \mathrm{~m}$ and $3 \mathrm{~m}$, with the thickest one being up to $8.7 \mathrm{~m}$ (Figure 3). Mudstone is dark grey and ash dark, and the thickness varies with various mudstone layers, which are mainly effective interlayers. 


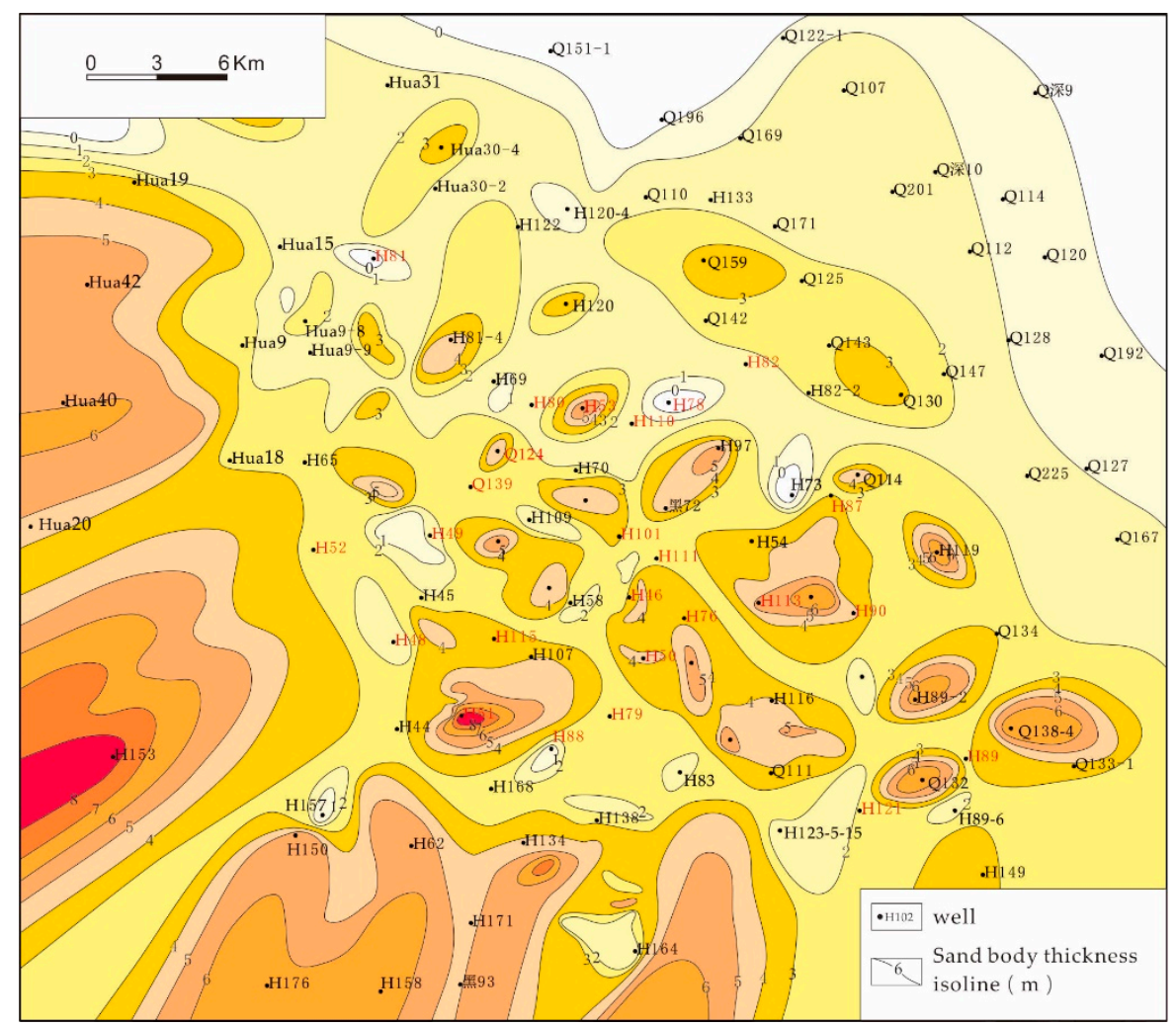

Figure 3. Distribution characteristics of the isolated bodies in Thin Layer 1 of Sand Bed I in $\mathrm{qn}^{2}$ member of Daqingzijing Oilfield. (The figure uses data from 1000 wells, and the producing wells are not be shown).

\subsection{Genetic Explanation of Isolated Sand Bodies}

\subsubsection{The Discovery of Storm Deposition Shows That There Is Higher Wave Energy in the Study Area}

The storm etching structures are various etching filling structures which are formed because of storm flows scouring and sapping sediments (Figure 4a). Scouring-filling structures remaining at the bottom of sediments are important signs to help identify tempestites [12-15]. Generally, hummocky cross beddings are sedimentary structures formed due to storm waves' impact (Figure $4 \mathrm{~b}-\mathrm{d}$ ), which is an outstanding feature of storm sediments [10]. Since a storm flow is a density current, numerous small burdens and ball-and-pillow deformation structures are founded in storm sediments in the Daqingzijing area (Figure 4e). They formed very thin deformation structural strata and were clamped in tempestites. Ripple marks on the top surface of lake tempestites are mostly symmetric and slightly asymmetric. The appearance of wave-ripple beddings is a sign of wave activities, and ripple marks in deep water are the evidence for the impact of storms (Figure 4f). 

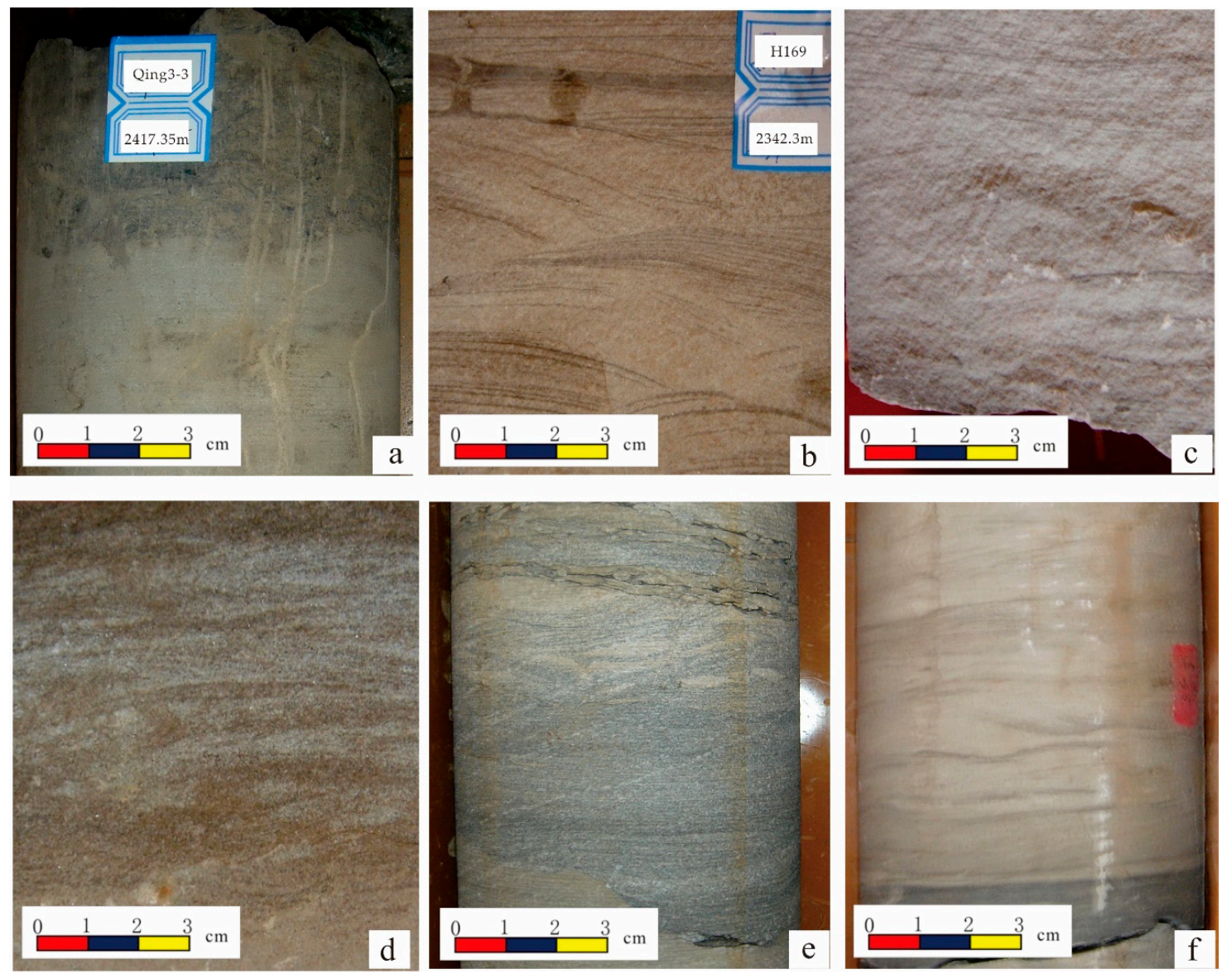

Figure 4. Photographs of cores of storm sediments. (a) Qing3-3, 2417.35m, scouring filling structure; (b) H169,2341.3m, hummocky cross bedding; (c) H169,2350.1m, hummocky cross bedding; (d) H169, 2342.5m, hummocky cross bedding; (e) H84, 2457.8m, slot mold structure; (f) H102, 2419.1m, wave ripple cross bedding.

In the Qingshankou Formation period of Daqingzijing Oilfield, there were storm sediments in the wells of Hei 83, Hei 84, Hei 109, Hei 102, and Qing 3-3. There were complete storm sequences in the wells of Hei 83, Hei 84, and Hei 109, and there were only thin stagnant strata caused by storm in Hei 102 and Qing 3-3. The appearance of storm sediments show that the water body of the lake basin in the study area was once deep in the period of Qingshankou Formation and was greatly influenced by storm waves (Figure 5). From a side, this reflects that waves played an important role in the formation of the sediment system of Qingshankou Formation. 


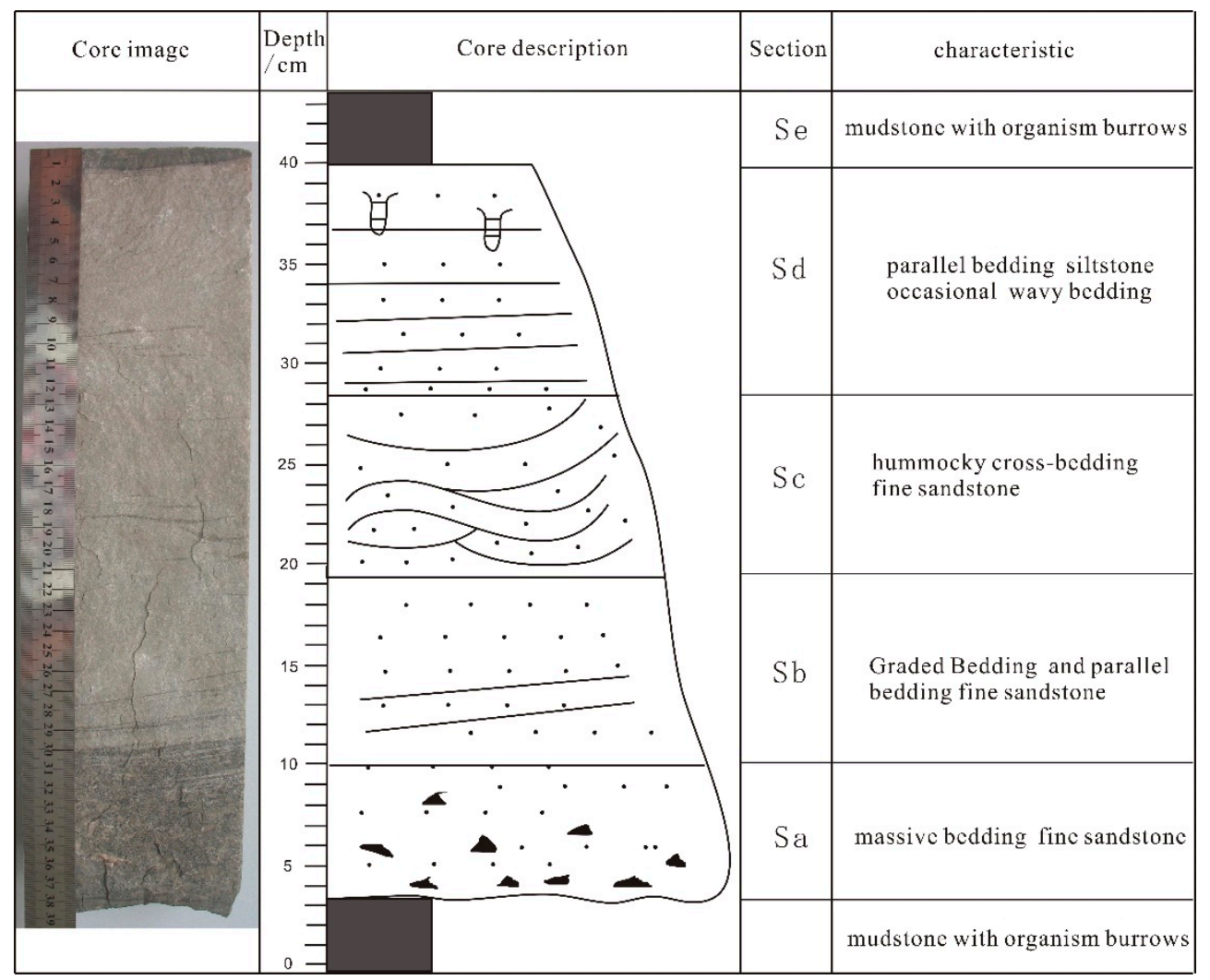

Figure 5. Characteristics of storm sediment sequence of Qingshankou Formation in Daqingzijing Oilfield.

\subsubsection{Broad and Gentle Offshore Slope Landform Is Conducive to the Formation of Isolated Bar}

In the depression phase of the Qingshankou Formation sediment period, the slopes of lake basins in Daqingzijing area were gentle, the terrain sloped gently, and the water body was rather deep. As the surface of the lake basins expanded, the generating area extended and the fetch reached farther. Waves on the lake surface arose rapidly from a storm, so the delta sand bodies formed in previous periods were discarded under a transgressive background and were sharply transformed by lake waves. As a result, sediments in delta plains did not grow or were in deficiency. Part of the front of bar sand bodies at the river mouth was transformed into isolated sand bodies or sand bodies interlinked with river mouth bars, namely front bar sand bodies, which lies in the front of bar sand bodies at the river mouth. Meanwhile, fragmentary materials from the delta front were re-carried by strong storm waves and formed dispersed offshore bar sediments on the broad and gentle offshore slopes.

The analysis on the mudstone color values show that mudstone colors turned from a partially reduced color into a partial oxidation color in the early and later periods of Qing2 member, which appears to be an obvious regressive process for a half-deep lake into a shallow lake. We chose 28 wells in Sand Bed V from the near to the distant on the plane according to the offshore line to make a diagram of mudstone color values so as to develop an environmental explanation and found that the water body between the shore line and the well area of Hei 89 is deeper and more stable, while the water body between the well areas of Hei 50 and Qian 139 is shallow with an oxidation-color-based shallow lake. The center of the lake basin is the sedimentary environment of the deep lacustrine facies. Seen from the plane, the shallow area with higher color values is oval-shaped or long and narrow, whose major axis is parallel with the shoreline in most parts (Figure 6). The comprehensive analysis reveals that in the front of the deeper area on the offshore side, the landform presents the characteristic similar to the offshore underwater paleohigh. 


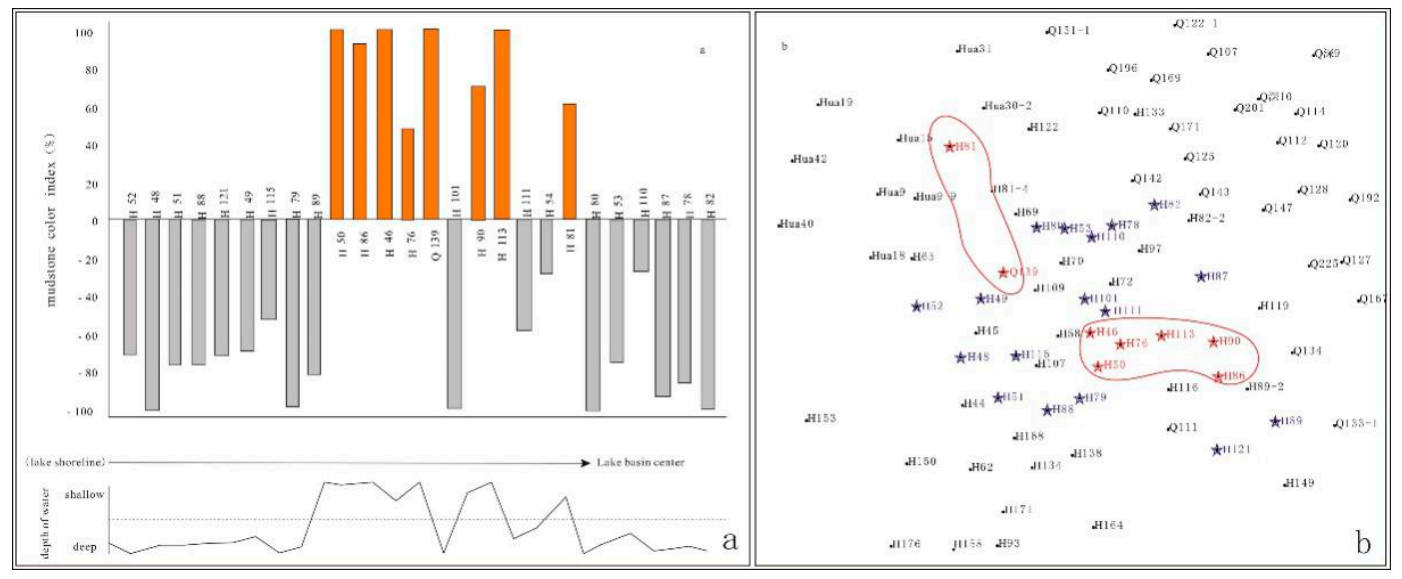

Figure 6. Mudstone Color Values of Sand Group V in Qiang-2 Member. (a) A diagram for water depth interpretation based on the analysis of mudstone color values; (b) A well position map (the asterisk is for the well in Figure 6a).

\section{Characteristics of Reservoir Accumulation in Isolated Bars}

Many great discoveries and $80 \%$ of the newly verified reserves in Jilin Oilfield these years are achieved in the delta front's thin interbeddings, which are in a relative large area. It is of great importance for exploration and development to conduct studies on the accumulation laws of the reservoirs in Daqingzijing Oilfield's lithology and strata. In this kind of reservoir, the development of the single sand body is relatively stable $[16,17]$. Due to the changes in lithology and physical properties, lithologic reservoirs were formed and the impact of gravitational differentiation on complex low-ultralow permeability reservoirs in the oil-water system, influenced by lithology and physical properties, is not obvious. Reservoirs are mainly single oil-bearing series, and faults and minor structures just act as an enrichment source. Accumulation is controlled by lithology and physical properties. Based on the outcrop observation over reservoirs, this article sets up the accumulation model of lenticular reservoirs as using the variables of 'Surrounded by source rocks to generate hydrocarbon', 'Driven by pressure differences', Migration through multi pathways' and 'Accumulation by filtering water'.

\subsection{Surrounded with Source Rocks to Generate Hydrocarbon}

The southern Songliao Basin experienced two major lake flooding events. The large number of aquatic organisms in the basin offered source materials for the formation of kerogen, and thus maintain rich organic materials for the dark mudstone of half-deep lake and deep lake facies. The dark mudstone in Qingshankou Formation and Nenjiang Formation indicates the two sets of regional high-quality source rock strata formed in the processes of the two lake water expansions. The dark mudstone in first and second member of Qingshankou Formation $\left(\mathrm{q}_{\mathrm{n}}{ }^{1}\right.$ and $\left.\mathrm{q}_{\mathrm{n}}{ }^{2}\right)$ is widely distributed with thicknesses ranging between $50 \mathrm{~m}$ and $150 \mathrm{~m}$.

Organic materials in dark mudstone in $\mathrm{qn}^{1}$ and $\mathrm{q}_{\mathrm{n}}{ }^{2}$ in Daqingzijing Oilfield are mostly made up of maceral composition of sapropelinite and exinite contents in a few samples are very high. Based on the analysis of organic material elements in kerogen, the organic materials in $\mathrm{q}_{\mathrm{n}}{ }^{1}$ member in the study area mainly belong to the I-type and II1-type with a few of them belonging to the II2-type, while organic materials in mudstone kerogen in $\mathrm{q}_{\mathrm{n}}{ }^{2}$ mainly belong to the I-type and II2-type, which have a better capacity for oil generation. With rock pyrolysis, organic materials in source rocks can also be classified and evaluated-organic materials in $\mathrm{qn}^{1}$ and $\mathrm{q}_{\mathrm{n}}{ }^{2}$ member mainly belong to the I-type and II1-type [18].

By using comparison fingerprint- chromatograms of crude oil samples and mudstone samples, as Figure 7 shows, the m/z 217 and m/z 191 fingerprints are very similar between crude oil and mudstone in the Qingshankou Formation. 

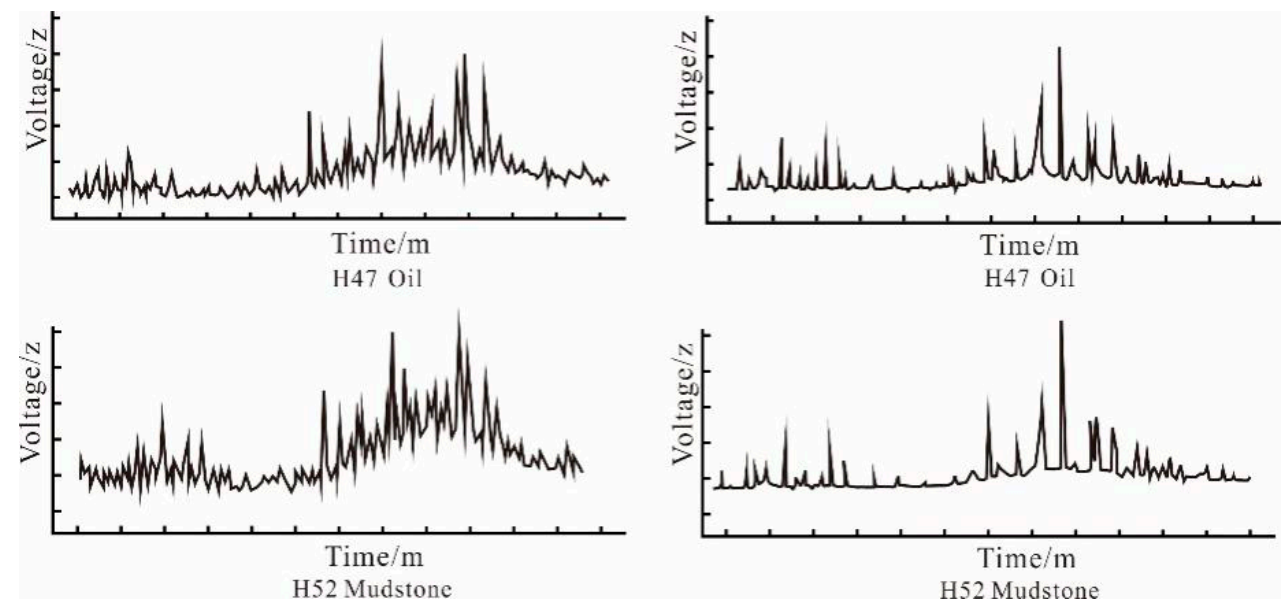

Figure 7. The m/z 217 and $\mathrm{m} / \mathrm{z} 191$ fingerprints between crude oil and mudstone in the Qingshankou Formation.

\subsection{Driven by Pressure Difference}

Oil and gas generated from source rocks enter into reservoirs after primary migration. Unlike in conventional reservoirs where buoyancy is the main source of migration power, the porosity and permeability in deep reservoirs are much lower than mid-level and shallow reservoirs $[19,20]$. This makes the interface tension between oil and gas and water-bearing rocks much larger than the buoyancy, so it is hard for oil and gas to float separately when driven by buoyancy. The abnormal high pressure in source rocks and the pressure difference (potential energy difference) between caprocks and reservoirs are necessary dynamic conditions for the formation of deep and native lithologic reservoirs.

Since the hydrocarbon migration in sandstone lens wrapped by mudstone can be seen as a special form of primary migration, this means there is a transfer of oil and gas from source rocks with particles of a low porosity and permeability to carrier beds and reservoirs with a relatively high porosity and permeability. The maximum migration distance can be up to $1 \mathrm{~km}$. Therefore, so to speak, as long as sandstone bodies are wrapped by or in contact with effective source rocks, the accumulation of oil and gas is sufficient.

The formation pressure measured data and calculating data prove pressure of mudstone reaches up to $22 \mathrm{MPa}$, and the sandstone pressure is close to normal hydrostatic pressure (Figure 8). Xiao et al. (1999) suggested, with their mudstone stress rupture experiments, that when the overpressure is larger than the mudstone ambient pressure $(10 \mathrm{MPa})$ in $\mathrm{q}_{\mathrm{n}}{ }^{1}$ member, abnormally high pressure (the overpressure value can arrive at over $10 \mathrm{MPa}$ ) flow will be released [21]. Hou et al. (2006) calculated that the pressure gradient at present increases gradually from Yaojia Formation down to $\mathrm{q}_{\mathrm{n}}{ }^{1}$ member and decreases sharply from the bottom of $\mathrm{q}_{\mathrm{n}}{ }^{1}$ member and Fuyang reservoir [5]. Based on this, they inferred that the abnormal pressure, which was generated from the end of Nenjiang Formation sediment period and Mingshui Formation sediment period to the peak period of oil generation and expulsion in the Neogene, was larger than mudstone fracture pressure. The overpressure value depends on hydrocarbon enrichment and the height of containing hydrocarbon. The overpressure's plane distribution range of source rocks in $\mathrm{q}_{\mathrm{n}}{ }^{1}$ and $\mathrm{q}_{\mathrm{n}}{ }^{2}$ member controls the hydrocarbon's plane distribution in the Gaotaizi reservoir. However, while the areas at the edge of the depression with low hydrocarbon-generating strength and overpressure distribute some structural changes because the thickness of dark mudstone in $\mathrm{q}_{\mathrm{n}}{ }^{1}$ and $\mathrm{q}_{\mathrm{n}}{ }^{2}$ members is very thin, the rest of the areas distribute changes in $\mathrm{q}_{\mathrm{n}}{ }^{1}$ and $\mathrm{q}_{\mathrm{n}}{ }^{2}$ members [22]. 


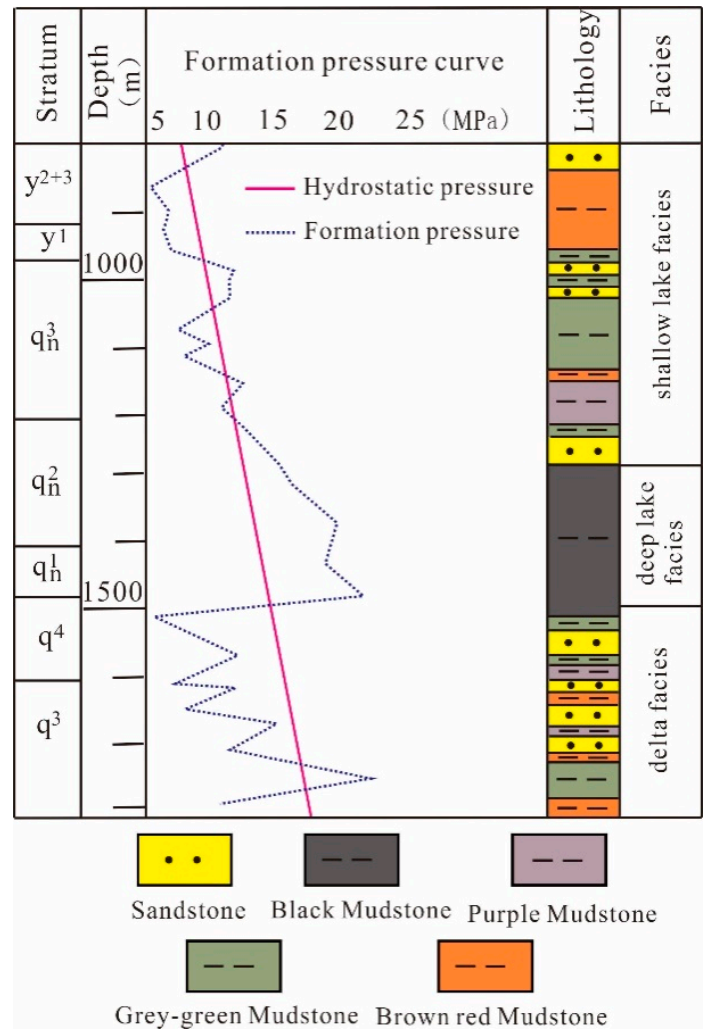

Figure 8. Formation pressure characteristics of the Xin171 well.

In lithologic reservoirs, the main factors controlling pressure difference are lithology-faults and fissures. The communication system between faults and fissures lies in the areas with relative low pressure and the argillite area is a high-pressure area. From mudstone to sandstone to fissure-fault system, a complete pressure gradient decreasing system is constructed.

\subsection{Migration Through Multi Pathways}

For a lenticular reservoir with low permeability, the faulting system is a main pathway for hydrocarbon migration [20]. The development of a faulting system determines the reservoir type and plane as well as its vertical distribution characteristics. On the west slopes and the central fault belt of Daqingzijing Oilfield, the faulting system has developed well. In the reservoir developing zone, the hydrocarbon migration amount is sufficient and larger capillary resistance can be overcome in the process of hydrocarbon migration. In addition, oil and gas expulsion is relatively complete. In this case, hydrocarbon accumulation is a lot more demanding for traps, which shows that reservoirs in the west slopes were mainly formed in fault structures, while on the east slopes of Daqingzijing Oilfield, the faulting system is relatively undeveloped and the hydrocarbon migration amount is not sufficient, which provides a much lower capacity for oil to expulse water. In the precondition of some certain capillary resistance, oil is not able to expulse water effectively in a certain range. This determines that the reservoir type on east slopes transforms gradually from lithologic structural reservoir to fault lithologic reservoir, eventually to lithologic reservoir. The oil-water relationship in each set of oil-bearing series is complicated (Figure 9a). 


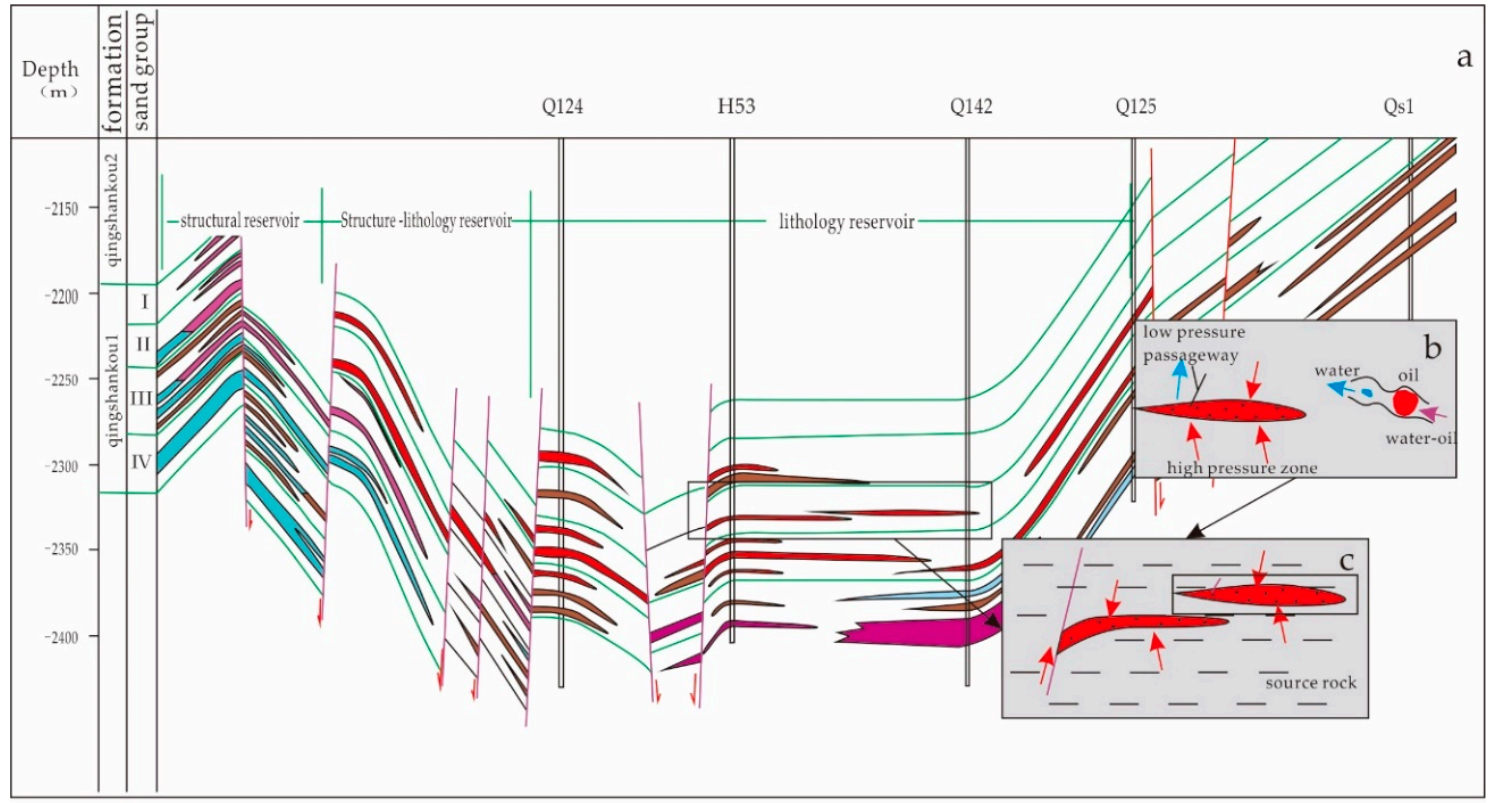

Legend

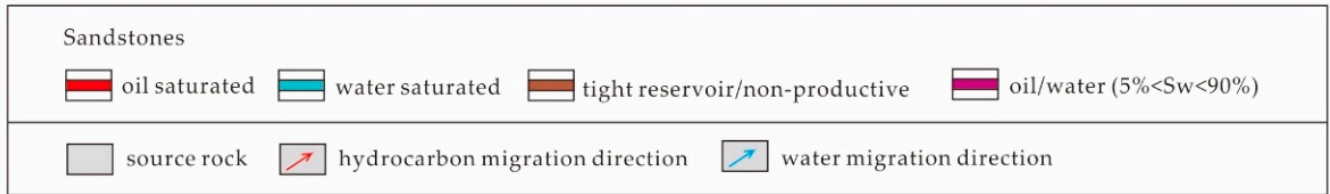

Figure 9. Reservoirs distribution and the accumulation characteristics of delta front sand bodies. (a) Reservoir Types and reservoir sector in Daqingzijing Oilfield; (b) Diagram of the Mechanism of filter-style accumulation; (c) Sketch of hydrocarbon migration direction.

\subsection{Accumulation by Filtering Water}

By studying the migration paths for oil, gas, and water in low-ultralow permeability reservoir, dynamic conditions, and non-Darcy seepage states [23], we suggest that the retention effect is crucial for oil to accumulate in lenticles. Study results show that when hydrocarbon migration happens in low-ultralow permeability reservoir, gas, and water migrates in the manner of single molecule or a few molecules combined and they can pass the bottleneck freely [24]. However, the minimum diameter of an oil droplet is larger than the diameter of the bottleneck, so it needs to deform to get through it. In this way, oil and water can be migrated in priority and the migration of oil droplets is not allowed. Then accumulation takes place. Pressure differences in fluids and buoyancy are the main factors affecting oil migration, while capillary resistance is the main resistance factor affecting oil migration. When the power is larger than the resistance, oil strands to form accumulation. In the syncline area, buoyancy inside reservoirs is smaller than capillary resistance, so normal gravitational differentiation does not happen between oil and water.

Indoor experiments and field production data show that reservoir wettability has a great influence on hydrocarbon migration. In the porosity of reservoir rocks where wettability is hydrophilic, the injected oil and water, which are wrapped in water films formed on the particle surface, move with many twists and turns. Most void water is expulsed and continuous hydrocarbon phases are formed. At this moment, buoyancy does not function at all. Oil droplets can form in the middle of larger drill ways and oil droplets are subjected to buoyancy, capillary resistance, and pressure.

Based on the analyses above, we put forward the mechanism of filter-style accumulation. The core contents include:

(1) The reservoir is a lenticular and low permeability reservoir. 
(2) From mudstone to sandstone to a fissure-fault system, a set of complete pressure decreasing system is constructed (Figure $9 b, c$ ).

(3) The retention effect is the main mechanism for water expulsion and oil retention in sandstone.

\section{Conclusions and Discussions}

(1) Based on the overview about the two decades of development experience in Daqingzijing Oilfield, this paper suggests that the isolated river-mouth bar sand bodies in the $\mathrm{q}_{\mathrm{n}}{ }^{1}$ member of Daqingzijing Oilfield with a background of delta sediments is a type of important oil and gas reservoir. However, the cause of the formation of numerous isolated river-mouth bar in the lake basin delta sediment system is a puzzle which vexes geographical researchers. To solve this problem, the authors obtained lots of evidence of storm waves' existence by using core observation. Combined with analyses of paleogeography and hydrodynamics, this paper gives a detailed discussion on the transformation of delta sand bodies by using waves and the genetic mechanism of an isolated river-mouth bar. In addition, on the basis of paleogeomorphology research and the sand body distribution statistics, we consider 'Storm waves conveying sand, landform controlling sand' as the cause and distribution model of the delta's isolated bar sand body formation. We also think the superposition of multiple bar sand bodies is the direct cause of the strong anisotropy in reservoir and the complex relationship between oil and water in reservoir. This conclusion mainly draws lessons from the sedimentary environment and sand body distribution of Apalachicola delta and assumes that the Qingshankou formation sedimentary period has the same characteristics, including modest wave energy, little tidal range, and a gentle offshore slope. This assumption does not rebel against the principles of sedimentology, and the conclusion is more closely aligned with the exploration and development and more reasonable in explaining hydrocarbon accumulation. Unfortunately, this kind of delta has not been found in the present lacustrine basin.

(2) Isolated sand bodies in the delta front mostly form lenticular lithologic reservoirs. Based on the outcrop observation over reservoirs, we think that the direct contact between source rocks and lenticular sand bodies is a precondition of the formation and existence of lenticular and lithologic reservoirs. From mudstone to sandstone to a fissure-fault system, a complete pressure gradient decreasing system is constructed. After water-oil mixing facies enter into sand bodies, water passes through sand bodies first and oil remains in sand bodies due to their different qualities.

Author Contributions: Conceptualization was conducted by P.C. and C.L., rock analysis by J.Z., formation pressure calculation by G.M., and sedimentary models research by Y.Z.; S.L. directed the revision of the manuscripts; P.C., C.L. and J.Z. contributed to the writing of the manuscript. The authors thank China National Petroleum Co., LTD, and Jilin Oilfield Corporation for supplying researching data and allowing us to observe the cores. All authors have read and agreed to the published version of the manuscript.

Funding: This research was funded by [Liaoning Revitalization Talents Program] grant number [XLYC1807129], [Liaoning Province Nature Fund Support Program] grant number [2019-MS-220] and [Talent Scientific Research Fund of LSHU] grant number: [XJJ2016-026].

Conflicts of Interest: The authors declare no conflict of interest.

\section{References}

1. Zhu, X.M.; Liu, Y.; Fang, Q.; Li, Y.; Liu, Y.Y.; Wang, R.; Song, J.; Liu, S.Q.; Cao, H.T.; Liu, X.N. Formation and sedimentary model of shallow delta in large-scale lake example from Cretaceous Quantou Formation in Sanzhao Sag, Songliao Basin. Earth Sci. Front. 2012, 19, 89-99.

2. Wei, Z.P.; Mao, C.L.; Sun, Y.; Miao, H.B. History analysis of petroleum reservoir fluids-Taking Sanma area in Huanghua depression as an example. Pet. Explor. Dev. 2002, 29, 11-13.

3. Zhao, Z.K.; Zhang, J.L.; Zhao, Z.Y.; Zhang, D.W. Reservoir Sedimentology in Southern Songliao Basin, 1st ed.; Petroleum Industry Press: Beijing, China, 2009; pp. 94-123. 
4. Yang, M.D.; Yang, M.H.; Tang, Z.X. Analysis of hydrocarbon distribution in Daqingzijing area of the southern Songliao Basin. Pet. Geol. Exp. 2003, 25, 252-256.

5. Hou, Q.J.; Wei, Z.S.; Zhao, Z.Y. Deep basin reservoir in Songliao Basin. Pet. Explor. Dev. 2006, 33, 406-410.

6. Zou, C.N.; Tao, S.Z.; Zhang, Y.Y. Lithostratigraphic reservoirs in the southern songliao accumulation $\mathrm{s}$ research and its significance in exploration. Chin. Sci. Bull. 2007, 52, 2319-2329. [CrossRef]

7. Li, C.L.; Qin, L.; Li, X.; Zhang, X.L. High resolution sequence stratigraphic frameworks research in the XII group of the member III of Qing Shankou formation in the Qian'an Oilfield. Mechatron. Control Eng. Appl. Mech. Mater. 2013, 339, 728-731. [CrossRef]

8. Coleman, J.M.; Wright, L.D. Modem River Deltas: Variability of Process and Sand Bodies; Broussard, M.L., Ed.; Houston Geological Society: Houston, TX, USA, 1975; pp. 99-150.

9. Coleman, J.M. Dynamic changes and processes in the Mississippi River delta. Geol. Soc. Am. Bull. 1988, 100, 999-1015. [CrossRef]

10. Feng, X.L.; Ma, L.X.; Deng, H.W.; Lin, H.X. The characters research and analysis on tempestite deposits of sandy beach-bar sediments in Dawangbei sag. XinJiang Geol. 2011, 29, 80-85.

11. Wang, Y.S.; Liu, H.M.; Gao, Y.J. Sandbody genesis and hydrocarbon accumulation mechanism of beach-bar reservoir in faulted-lacustrine-basins: A case study from the upper of the fourth member of Shahejie Formation, Dongying Sag. Earth Sci. Front. 2012, 19, 100-107.

12. Yalçin, M.N.; Littke, R.; Sachsenhofer, R.F. Thermal History of Sedimentary Basins. In Petroleum and Basin Evolution; Welte, D.H., Horsfield, B., Baker, D.R., Eds.; Springer: Berlin, Germany, 1997.

13. Gareth, T.G. Characterisation and high resolution sequence stratigraphy of storm-dominated braid delta and shoreface sequences from the Basal Grit Group (Namurian) of the South Wales Variscan peripheral foreland basin. Mar. Pet. Geol. 2000, 17, 445-475.

14. Colombié, C.; Bádenas, B.; Aurell, M.; Götz, A.E.; Bertholon, S.; Boussaha, M. Feature and duration of metre-scale sequences in a storm-dominated carbonate ramp setting (Kimmeridgian, northeastern Spain) Original Research Article. Sediment. Geol. 2014, 312, 94-108. [CrossRef]

15. Gerd, M.; Sytze, V.H. Response of wave-dominated and mixed-energy barriers to storms. Mar. Geol. 2014, 352, 321-347.

16. Li, J.Z.; Yang, T.; Wang, L.W.; Jiang, T. The fault structure and its controlling role to hydrocarbon accumulation in Daqingzijing area, Southern Songliao Basin. Pet. Explor. Dev. 2004, 31, 18-20.

17. Wei, Z.S.; Song, X.M.; Tang, Z.X.; Chu, X.; Yang, G. Sedimentary facies and lithologic oil pools of the Upper Cretaceous Qingshankou Formation in Daqingzijing area, Changling Sag, southern Songliao Basin. Pet. Explor. Dev. 2007, 34, 28-33.

18. Li, Z.Q.; Xiao, M.D.; Hou, Q.J. Ancient type foreland basin found deep songliao basin and the gas geological significance. Reg. Geol. China 2002, 21, 689-690.

19. Zhang, D.W.; Chen, F.J.; Cheng, G. The microscopic features of pore structure in Gaotaizi oil layer of Daqingzijing area. Oil Gas Geol. 2006, 5, 668-674.

20. Zhang, F.Q.; Wang, Z.L.; Wu, F.L.; Gao, X.J.; Luo, R.H. Dynamic analysis on hydrocarbon migration of accumulation periods in low permeability-tight sandstone reservoir. J. China Univ. Pet. (Ed. Nat. Sci.) 2012, $36,32-38$.

21. Xiao, D.M. Theory and practice of lithologic reservoir exploration in the syncline area of the northern songliao basin. Res. Ind. 1999, 9, 4-7.

22. Wei, Z.P.; Mao, C.L.; Sun, Y.; Miao, H.B. Oil and gas accumulation process in Daqingzi region of southern Songliao basin. Pet. Explor. Dev. 2002, 29, 11-16.

23. Yang, W.W.; Liu, G.D.; Liu, X.Y. The accumulation models of oil in the low permeability reservoir of Yangchang formation in longdong area, Ordos Basin. Earth Sci. Front. 2013, 20, 134-139.

24. Li, H.B. Oil-displacement system with ultra-low interfacial tension for reservoirs of different permeability under different wettability on rock surface. Acta Pet. Sin. 2008, 29, 573-576.

(C) 2020 by the authors. Licensee MDPI, Basel, Switzerland. This article is an open access article distributed under the terms and conditions of the Creative Commons Attribution (CC BY) license (http://creativecommons.org/licenses/by/4.0/). 